\title{
2017 Award for Mathematics Programs That Make a Difference
}

\author{
Allyn Jackson
}

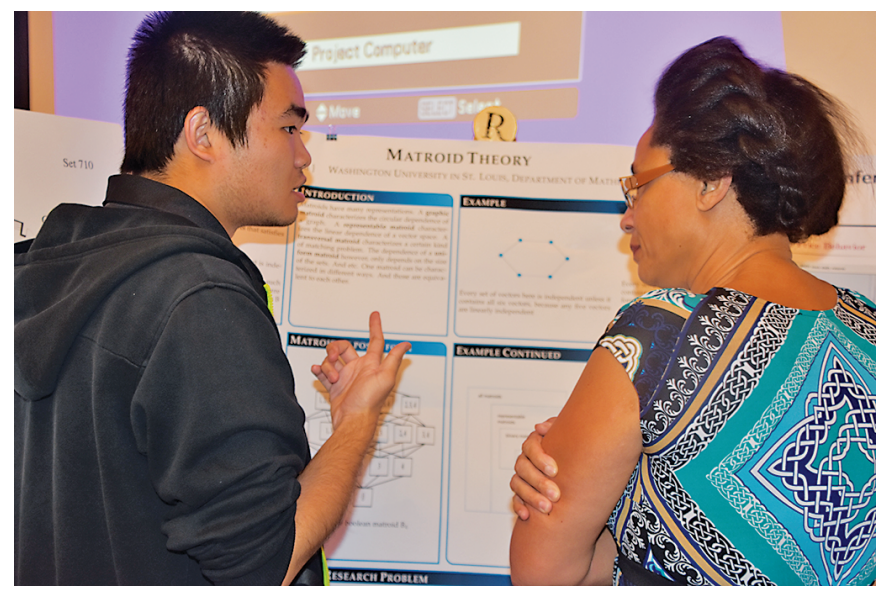

The Field of Dreams conference gives students a chance to discuss mathematics, as at this poster session.

Each year, the AMS Committee on the Profession (CoProf) chooses outstanding programs to be designated as Mathematics Programs That Make a Difference. For 2017 CoProf has selected the MATH ALLIANCE.

\section{Citation}

Be it resolved that the American Mathematical Society and its Committee on the Profession recognize the National Alliance for Doctoral Studies in the Mathematical Sciences (the Math Alliance) for its programs over the last 10 years promoting participation by groups underrepresented in doctoral programs in the mathematical sciences.

Now based at Purdue University, the Math Alliance began in 2001 as a partnership of three Iowa State Regents universities and four Historically Black Colleges and Universities and has grown into a national network of institutions and faculty that mentor minority students

Allyn Jackson is senior writer and deputy editor of the Notices. Her e-mail address is axj@ams.org.

For permission to reprint this article, please contact:

reprint-permission@ams . org.

DOI: http://dx.doi.org/10.1090/noti1516 in both undergraduate and graduate programs. It holds the annual Field of Dreams Conference, attended in 2015 by 174 undergraduates and 130 faculty from over 115 institutions. In addition, Alliance Mentors work at the predoctoral, masters, $\mathrm{PhD}$, and post-doctoral level to help students succeed in their studies and progress on to the next level. In 2015-16 the program listed 552 faculty mentoring over 600 active scholars. The Alliance has expanded its network 30 -fold over the last 10 years, and has recently been used as a model for a similar program in physics by the American Physical Society.

One of the supporting letters for the nomination, by a former Alliance Scholar, credits the Alliance with helping to "mold an African-American female from rural Louisiana who had never considered going to graduate school into a NSF postdoctoral fellow." Another, by the chair of a participating institution, describes "a community aspect of the Alliance that is hard to capture in numerical data - an aspect that is best experienced at one of the annual Field of Dreams Conferences or in a department with a nontrivial number of minority graduate students."

The AMS commends the Math Alliance for its commitment to and success in increasing minority participation in doctoral programs nationwide.

\section{Program Description}

In the 1990s the mathematics department at the University of Iowa embarked on an effort to recruit and retain graduate students from members of groups underrepresented in mathematics. Through careful attention to mentoring and by observing what helped the students succeed, the department underwent a transformation that refocused its commitment to serving all students well. Seeking to expand these efforts, it formed a partnership with the math departments on the other two Iowa State Regents campuses-Iowa State University and the University of Northern Iowa-and with several historically black colleges and universities. The success of this work was recognized by the AMS Award for an Exemplary Program or Achievement in a Mathematics Department, which went to the University of Iowa in 2008 and to Iowa State University in 2015. 
It is from these roots that the Math Alliance has grown. That it started in Iowa, where the population is predominantly white, and in math departments with predominantly white faculty has provided an example and an inspiration that many other departments have begun to follow.

The main purpose of the Math Alliance is to ensure that students from underrepresented groups who have the ambition and desire to pursue graduate study in the mathematical sciences have an opportunity to do so in a supportive environment. The Alliance helps students realize their potential for graduate work in these fields and nurtures them in their journey to becoming math science professionals. More broadly, the goal of the Alliance is to spark a spiritual transformation within mathematical sciences departments so that they set aside the traditional model of weeding students out and embrace an inclusive model of helping all students succeed.

While originally focused on minority groups, today the Math Alliance aims to serve a wider collection of "underrepresented" students: those who are US citizens or permanent residents and who come from ethnic groups, families, and/or regions that have had little prior experience with doctoral study in the mathematical sciences. This shift reflects a deeply held value of the Math Alliance community and an understanding that many citizens come from backgrounds that have historically lacked opportunities to pursue STEM careers. For example, the Math Alliance has worked closely with the math department at Eastern Tennessee State University, which sent approximately twenty of their students to the most recent Field of Dreams conference. While most of these students are not from minority backgrounds, they come from a region of the country that is underrepresented in the math sciences. As a result of this broadening of focus, about 85 percent of the students served by the Alliance are from minority backgrounds, and it is expected that this number will vary as the profession evolves.

The Math Alliance has a nationwide network of mentors, organized regionally, who are at institutions with a substantial proportion of undergraduates from underrepresented groups. These mentors nominate undergraduate math sciences majors and master's students to become Alliance Scholars, who then become eligible for various Alliance programs. In addition to advising and supporting the students, the mentors share ideas with other likeminded faculty to help spread the Math Alliance spirit.

Each Alliance Scholar is paired with at least one mentor and has the opportunity to participate in Alliance summer research experiences for undergraduates programs. Alliance Scholars attend the annual Field of Dreams conference, which has been held each fall since 2007. Drawing about two hundred students and about one hundred faculty members, Field of Dreams has become a magnet for minority students interested in mathematics or statistics as well as a recruiting event for Alliance institutions. Other quantitative fields, such as engineering and business, are also represented. At the conference, students build friendships, get to know mentors, find out how to prepare

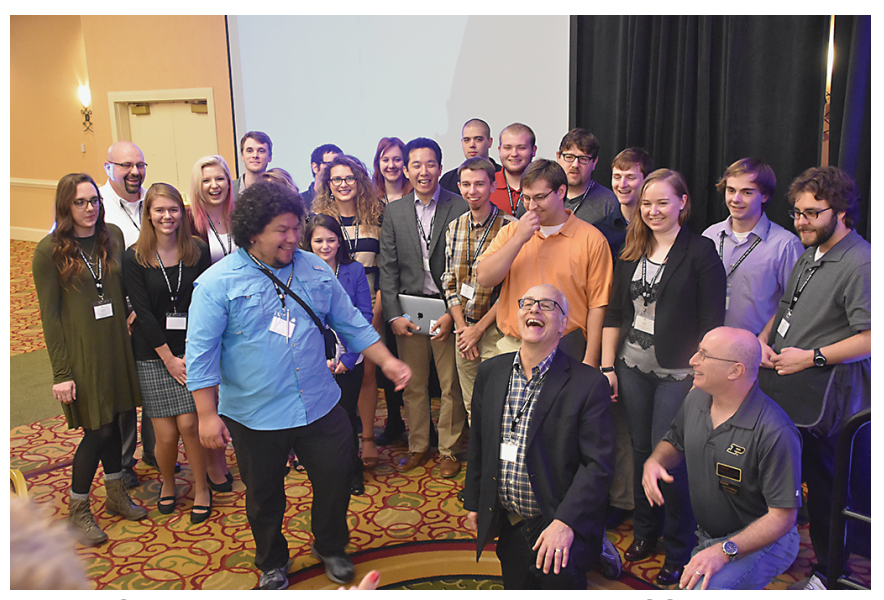

Field of Dreams participants have a lot of fun, even when posing for group photos. Laughing at the front of the group is Math Alliance director Phil Kutzko. At right kneeling is executive director David Goldberg.

for and apply to graduate school, and learn about career opportunities. In addition to helping students, Field of Dreams strengthens ties among Math Alliance mentors.

The Alliance has worked with faculty in graduate programs across the nation to build Alliance Graduate Program Groups. These are groups of faculty in departments that have made a commitment to the Alliance spirit of helping all students succeed and of providing a friendly, welcoming community within the department. Today there are thirty-five Graduate Program Groups, and several other departments have applied to join.

One of the most successful programs of the Math Alliance is called Facilitated Graduate Applications Process (FGAP). Its purpose is to provide undergraduate seniors and master's students with the advice and assistance needed to successfully apply to graduate programs. Each student is paired with a faculty member at a Graduate Program Group who serves as the Alliance Doctoral Mentor. The student, the doctoral mentor, and the predoctoral mentor form the graduate mentoring team, which helps the student decide which doctoral programs to apply to and assists the student with all aspects of the application process. F-GAP has placed more than two hundred students in math sciences graduate programs over the last three years.

In 2016 the Math Alliance moved to its present home at Purdue University. One of the founders of the Math Alliance, Philip Kutzko, of the University of Iowa, is the director, and David Goldberg, of Purdue University, is the executive director. ${ }^{1}$ Edray Goins, who also serves as the president of the National Association of Mathematicians, is the associate director of the Math Alliance. The work of the Math Alliance has received support from the National Science Foundation since 2002. One of the present goals is to institutionalize the Math Alliance to make it a self-supporting organization, and the move to Purdue,

${ }^{1}$ The September 2016 issue of the Notices carried an interview with David Goldberg; the interview was conducted by Notices associate editor Harriet Pollatsek. 


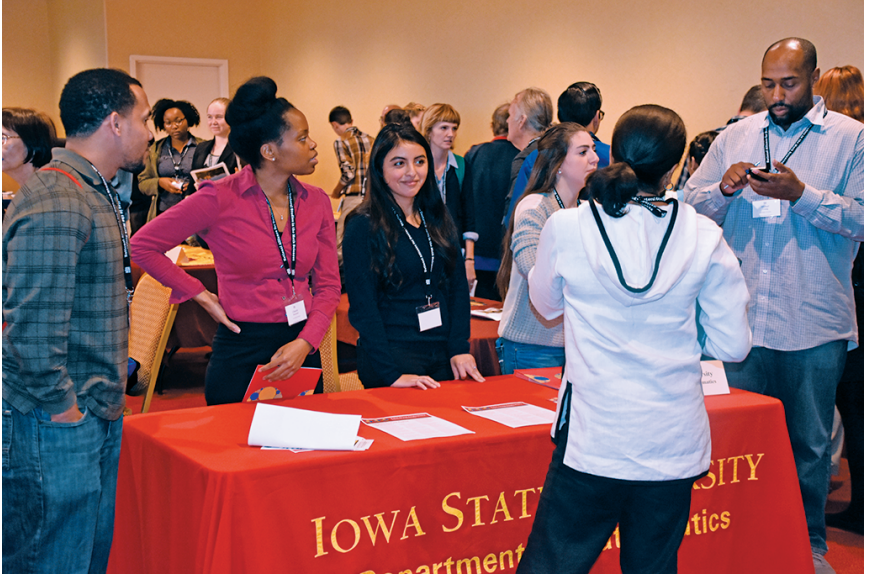

Institutions from all over the country send representatives to the Field of Dreams conference.

which has generously provided bridging support, may be seen as a move in this direction.

Math Alliance website: matha11iance.org

\section{About the Award}

CoProf created the Mathematics Programs That Make a Difference designation in 2005 as a way to bring recognition to outstanding programs that successfully address the issue of underrepresented groups in mathematics. Each year CoProf identifies one or two exemplary programs that:

1. aim to bring more individuals from underrepresented minority backgrounds into some portion of the pipeline beginning at the undergraduate level and leading to an advanced degree and professional success in mathematics or retain them in the pipeline,

2. have achieved documentable success in doing so, and

3. are replicable models.

The CoProf subcommittee making the selection for this year's awards consisted of Al Boggess, Duane Cooper, Pamela Gorkin, and William McCallum (Chair).

Previously designated Mathematics Programs That Make a Difference are:

- the graduate program at the University of Iowa and the Summer Institute in Mathematics for Undergraduates/ Research Experience for Undergraduates at Universidad de Puerto Rico, Humacao (2006);

- Enhancing Diversity in Graduate Education (EDGE) and the Mathematical Theoretical Biology Institute (2007);

- the Mathematics Summer Program in Research and Learning (Math SPIRAL) at the University of Maryland and the Summer Undergraduate Mathematical Science Research Institute at Miami University (Ohio) (2008);

- the Department of Statistics at North Carolina State University and the Department of Mathematics at the University of Mississippi (2009);

- the Department of Computational and Applied Mathematics at Rice University and the Summer Program in Quantitative Sciences, Harvard School of Public Health (2010);
- the Center for Women in Mathematics at Smith College and the Department of Mathematics at North Carolina State University (2011);

- the Mathematical Sciences Research Institute (2012);

- the Nebraska Conference for Undergraduate Women in Mathematics (2013);

- the Carleton College Summer Mathematics Program and the Rice University Summer Institute of Statistics (the latter now at the University of Nevada at Reno) (2014);

- the Center for Undergraduate Research in Mathematics at Brigham Young University and the Pacific Coast Undergraduate Mathematics Conference (2015);

- the Department of Mathematics at Morehouse College (2016).

\section{Photo Credits}

Photos are courtesy of Donald Cole. 